\title{
The Role of Information Exchange in Supply Chain Collaboration: A Case Study of a Vietnam Ship Parts Supplier
}

\author{
Judith Molka-Danielsen \\ Molde University College, NO \\ J.Molka-Danielsen@himolde.no
}

\author{
Bich Thi Ngoc Le \\ Molde University College, NO \\ BichLe@ sundgaarden.no
}

\author{
Per Engelseth \\ Molde University College, NO \\ Per.Engelseth@himolde.no
}

\begin{abstract}
This research paper examines collaborative supply chain strategies of an anonymized company in a developing region, hereafter called Ship Parts (SP) Vietnam, a pipes and valves supplier for the shipbuilding industry. Our research applies descriptive analysis approach to examine the question; what is the role of information exchange in customer collaboration practices in management of the supply chain. We examine the practice of Vendor Managed Inventory in these relationships. The units of analysis are different types of relationships that SP Vietnam has with its key customer stakeholders in its network. The names of all key stakeholders are all anonymized. In this paper we investigate SP Vietnam's relationship only with its customers. These include longtime international partner WAKE, the newly acquired Japanese customer Chūbu Shipyard (Chübu), and the growing potential customer VESSELS Group in Vietnam.
\end{abstract}

\section{Introduction}

Collaborative supply chain is defined as a system with two or more companies that jointly work to plan and execute supply chain operations that lead to greater success than when acting in isolation. Companies are motivated by potential benefits of shared information system and suitable partnership strategies, recognizing that information breakage is one of the main reasons leading to poor supply chain performance [1] [2]. In this study, we ask the research question; what is the role of information exchange in the customer collaboration strategies that are being applied to manage supply chains in customer relationships. Space does not permit analysis of SP Vietnam's relationship with its suppliers in this paper. We present a literature review that addresses the concepts of information system with a focus on information sharing in a supply chain. This paper has a strong focus on Vendor Managed Inventory as collaborative exchange strategies due to the strong relationship between the case company and its customer WAKE. We therefore analyze the relationships between Ship Parts Vietnam and its customers in light of the applied information exchange strategies. The research question on the role of information exchange is further explored by reflective analysis of the case, on whether the relationship model shared by SP Vietnam and WAKE can be applied for SP Vietnam's other customers. Our findings suggest that trust is an important factor in the success of their relationship. SP Vietnam believes that the success of its collaboration with its customers can lead the way for SP Vietnam to reach out to more customers in the developing Asia region.

\section{Literature Review}

As organizations are open systems that constantly interact with their environment, it is logical that the need for information is significant. According to [3], companies or organizations draw resources from the external environment (inputs), transform them into outputs and pass them back to the environment. Information about inputs could include the cost and availability of materials, delivery quantity and schedules; sales data, etc. Output information can be customer satisfaction, service level, goods or services, etc. Within companies, managers depend on a flow of accurate and timely information in order to make internal processes efficient, integrate different functions within the business, and create electronic links with customers. In a supply chain perspective, it is undeniable that the needs for information remain significant, if not amplified.

\subsection{Information Quality}

According to [4], information quality refers to the degree with which the information shared by one partner meets the needs of the other partners. Information, particularly the transparency and quality of information flows play a crucial role in ensuring the effectiveness of supply chain activities. McGowan in [5] argued that the information system 
is perceived useful when the information is of high quality, readily accessible, accurate and relevant. Further, information quality is conceptualized in terms of accuracy, convenience of access and reliability [5]. The impact of environmental uncertainty, intra-organizational facilitators, and inter-organizational relationships on information sharing and information quality in supply chain management are studied using data collected from 196 organizations [6]. Results suggest that trust and shared vision among partners have a strong influence on the quality of shared information. Good information sharing program and strategies can help reducing information asymmetry in the supply chain, and consequently help avoiding opportunistic behaviors and sub-optimal decisions [7] [8]. As we describe different types of collaboration between the cases company and its customers, it is clear that different types of relationships have impact on the adopted information sharing strategy.

\subsection{Information Content}

Zhou and Benton criticized the fact that many managers, with concern for information sharing, focus only on the technology behind the act, i.e. the software and hardware that enable the sharing of information [4]. However, it is the way companies use the information that lead to differences in performances [4]. This indicated that investing in information technology alone is not enough, and only when managers pay equal attention to both technology investment as well as the process of choosing the right information to share and putting the information into use, can a firm achieve effective performance. Information content can include data such as supplier information, manufacturer information, customer information, distribution information, and retailer information [4]. It can also refer to different specific types of information such as sales data, available materials, production plans, etc.

\subsection{Vendor-Managed Inventory (VMI)}

Inventory management is one of the most important issues in the entire supply chain management. Various studies have been carried out in order to provide companies the most optimal methods to control their inventory so that inventory costs can be kept at the lowest level possible while providing the best service to their upstream customers. Several such concepts and models are the re-order point, economic order quantity (EOQ), or economic batch quantity (EBQ), etc. These sophisticated models are needed to enable accurate and timely planning and control of logistics in a focal firm [9]. Nevertheless, a company cannot stand alone in the market, and usually is at the center of many possible connections with other suppliers and customers companies. This position in the industry put the focal firm in a difficult situation, as upstream process such as distribution and retail for both finished products and spare parts are subject to independent, random demand, which can increase the fluctuation of demand and consequently make detailed inventory planning a big challenge. When it comes to coordinating logistics among supply partners, a major consequence that can be generated from poor coordination is amplification of changes in demand upstream, which are often referred to in scientific studies as the bullwhip effect [1][10][11]. Vendor-Managed Inventory (VMI) is a coordinating program to overcome this challenge. Various studies define VMI as an approach to inventory and order fulfillment whereby the supplier, not the customer, is responsible for managing and replenishing inventory $[9][12][13][14]$. This is said to be the practice to counter the traditional pull scheduling, in which orders quantity and delivery time are mainly decided by the retailers. Under VMI, the manufacturers decide how many and when to send the next order. In other words, the suppliers assume responsibility for monitoring sales and inventory and use this information to trigger replenishment orders. In practice, the basis on which decisions will be made is agreed with the retailer beforehand, and it is based on the retailer's sales information. According to [15], VMI relationships have received significant attention among researchers. When defining a collaboration program based on VMI concept, some authors suggest a difference in the level of integration based on the time taken to transfer ownership of the goods. There are practices where the ownership of the goods is transferred to the customers upon dispatch or on arrival at customer's warehouse, and the supplier is only responsible for the replenishment process.

\subsection{VMI relationship and Information Sharing}

Information plays a crucial part in creating a smooth coordination throughout the supply chain, especially when VMI is applied. When taking the replenishment responsibility, the supplier will need some type of information about the customer's demand. There should be three issues involved in the information sharing process within a VMI relationship which are type of data, transfer means and transfer frequency [16]. Any information affecting customer's inventory status is valuable for 
the supplier, but the most important information is inventory level.

Trust is an important component of any relationship, thus it is undeniable that this is a vital part of VMI relationships as well. There might be different types and levels of trust and commitment exist between supply chain partners, depending on duration of the relationship and previous interaction experience [15]. There should be a certain level of trust being established and developed between the involved parties in order for VMI to be successful [17]. This is due to the fact that among all data being transferred back and forth between parties, confidential information might be included. Thus, by involving in VMI with unreliable partners, companies risk being in an undesirable situation where the information is exposed to their competitors. Clearly, this situation should be avoided at all costs, which explains why companies only establish successful VMI relationship with partners that they already developed a good level of trust with. Another issue related to trust in VMI also concerning the performance of the other party in the VMI agreement. Accordingly, in order for VMI to be established successfully, parties should be able to demonstrate a record of long-term good performance. This notion can help develop trust and reduce the perceived risk of collaborating with a badly performed partner [17]. Several studies find trust in groups to have a cultural component in both face-to-face and semi-virtual relationships in how it develops $[18,19]$ e.g. finding factors of honesty to be important in the Chinese culture and in the Dutch culture individual performance to play an important role. Being a vital ingredient of a VMI relationship, trust ensures that the parties fulfil their obligations, and only long term relationships built on mutual benefits and trust are likely to succeed [13].

There have been a number of studies concerning benefits of engaging in a VMI relationship. Among these is mentioned the benefit of VMI's ability to reduce bullwhip effect, which has been previously mentioned as one of the main reasons companies initiate inter-member logistics program. The implication that VMI is having the supplier take the decision on replenishment aims to minimize the impact of demand amplification [9]. The ability to dampen this critical impact of infrequent and large orders is said to be the key to success of VMI. This type of collaboration can also help reduce the surplus capacity and excess finished goods held by suppliers to counteract such variation. There is also immediate benefit to a supplier engaged in VMI; the access to data on customer sales as well as inventory levels at the customer's warehouse. It is assumed that the supplier can use these data to provide better control of the supply chain, thus creating benefits for not only themselves but also the customers. In a review two main benefits, performance improvements by demand visibility and costs improvement of VMI collaboration were suggested [15]. However, setting up an intra company's collaboration program is not an easy task and can face various problems in all phases. Factors that can prevent organizations from achieving successful VMI implementation include [9, 15]:

- Unwillingness to share data

- Investments and restructuring costs

- Lack of standard procedures

- Vulnerability, agreement on liability, trust, confidentiality and risk of information abuse;

- Quality of shared data, seasonal variations and forecasting quality;

- Ability to utilize information to improve performance;

- Geographical distance between parties;

- Inventory ownership;

- Critical volume.

Different areas in the supply chain activities make proper implementation of VMI a great challenge.

\subsection{Framework for Examining Collaborative Supply Chain Strategies}

The literature review points out the necessity of collaboration in supply chain management. This analysis will adapt the framework developed by Derrouiche et al. that includes five criteria: extent of collaboration, objects involved in the collaboration, nature of collaboration, decision levels, and frequency of decisions [20]. This framework will be applied to understand the characteristics in the relationship that the case company has with its customers. In terms of extent of collaboration, they suggest two types of external integration: bi-level with direct suppliers and customers; and multi-level that is a complete integration of the whole supply chain. Objects involved in the supply chain collaboration are represented in a five-level object hierarchy introduced includes: data, information, knowledge, expertise and capability [21]. Nature of integration of objects types is listed as: make objects available; exchange objects sequentially; share objects - two partners use the same set of objects. Decision levels and frequency can be long term (strategic), medium term (tactical) and short term (operational). The cartography in Figure 1 summarizes the components (further elaborated in the Discussion section Table 4). The MIN curve represents the collaborative relationship at the operative level. The MAX curve shows the best 
collaborative practices that enable partners to share sets of strategic information, responsibilities, and risks with all partners of the first tier.

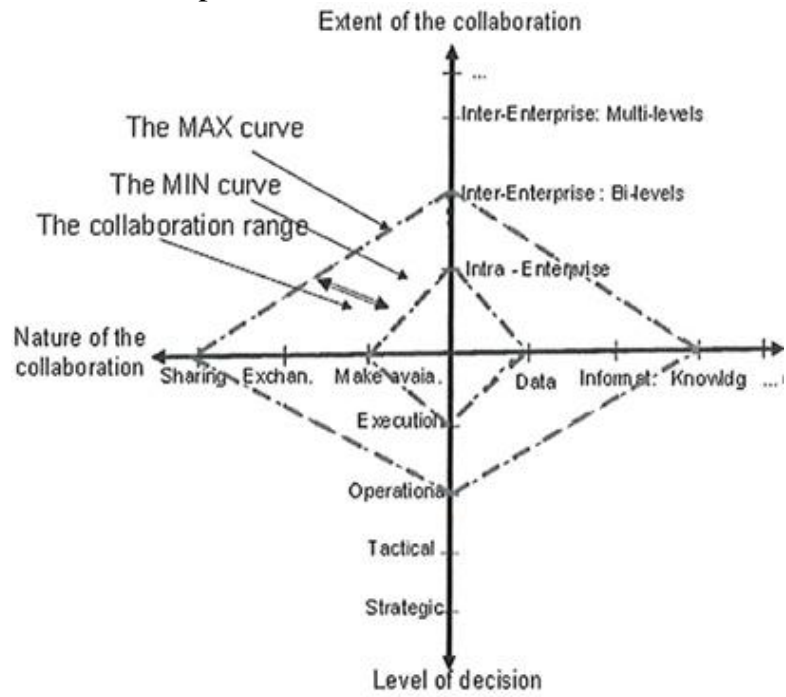

Figure 1. Cartography of collaboration (adapted - [20])

\section{Methodology}

We apply a descriptive case study method in studying the relationships between SP Vietnam and its network of customers. The data collected in this study include: information of SP Vietnam's customers, the proportion of SP Vietnam's sales regarding each customer, and methods of communicating with customers. In order to collect this data, eight semi-structured interviews were conducted as face-to-face interview by one of the coauthors, with SP Vietnam in April 2015, its customers in January 2016, and follow-up computerassisted (Skype) interview from March to May 2016. These were voice recorded, and transcribed by the same co-author. Content was validated later by email with the interviewee. At the case company, most information is provided by the general manager. Information regarding the case company's biggest and second biggest customers were collected onsite via face-to-face interviews. Informants from these companies are Procurement Manager/Sourcing Manager. It can be argued that the choices of sample in this paper cover almost all members of the case company's customer-side supply chain network. Additionally, informants from the most important source, the case company, are both in manager and operational positions.

\section{Case Description}

SP Vietnam is the subsidiary company of the SP Group in Norway. SP Group works within customer segments plumbing, marine, oil \& gas, hydropower and transportation and communications. Within the marine and oil and gas sector SP Group supplies products such as pipes, piping products and valves, as well as technical solutions to the customers. The group operates at 72 locations in Norway and has several subsidiaries and export business, with a total of 1,500 employees and a turnover of over 6 billion NOK. The company is part a French industrial group.

SP Vietnam was established in 2009, as a strategic decision toward one SP AS's long-term customer WAKE AS. Already in 2007, WAKE had opened a shipyard in Vung Tau, Vietnam. Even though being a daughter company within the SP Group, SP Vietnam is operated as an independent company. At the time when SP Vietnam was first established, besides WAKE, SP Vietnam also had contracts with other customers, including the biggest Vietnamese shipyard. In 2012, SP Vietnam moved to its current location, which is next to WAKE shipyard in Vung Tau, Vietnam to stay close to WAKE. The company's day-to-day business is to sell equipment. Some of the company's biggest customers include WAKE shipyard, Chūbu shipyard, and the VESSELS Group. The company is also approaching some customers in the region, including a Shipbuilding Cooperation and shipyards in Vietnam and Singapore. According to the general manager of the company, SP Vietnam has struggled significantly with inventory since the bankrupt of one of its customers in 2010. Items that were supposed to be used by this customer was stocked both inside and outside the warehouse, creating various inventory problems for the company, as most of them cannot be sold to other customers due to the difference in the items' dimensions. This issue lasted until 2015. An opportunity to reach for more customers developed in 2015 when SP Vietnam received their own export right. The relationship between SP Vietnam and its customers are introduced in Table 1.

Table 1. SP Vietnam and customer relationships

\begin{tabular}{ll}
\hline Customer Description & Relation to SP Vietnam \\
\hline WAKE Group/WAKE & - current biggest customer \\
Vungtau & 55\% of SP-V sales; 20\% \\
- Norwegian shipbuilder of & of WAKE Vungtau total \\
specialized vessels for oil & purchases \\
and gas industry; 10 & - Frame agreement: 1 \\
shipyards in 4 countries: & ship-set of standard \\
delivered 12 vessels in & items \\
2015 & - VMI application \\
- WAKE Vungtau: & - SP Vietnam manages \\
activities from hull & WAKE's redundant \\
construction to full & items \\
vessels delivery; & - Intense information \\
delivered 3 out of 12 & exchange, solely based \\
vessels in 2015 & on emails, phone calls \\
& and meetings. \\
\hline
\end{tabular}




\begin{tabular}{l|l}
\hline Chūbu Shipyard & - Collaborated since Dec. \\
- Est. 1905, in 2003 started & 2014, together with SP \\
"new" shipbuilding, ship & Norway \\
repairing and steel & -4 projects in total, 2 \\
production work & finished and 2 near end \\
- 200 employees, with & - total sales counted up to \\
capital of 300 million & 9.4 million NOK (16\% \\
Japanese Yen (22 million & of the total sales) \\
NOK) & - Joint force between SP \\
& Vietnam and SP Norway \\
\hline VESSELS Shipyard and & - started working with the \\
VESSELS Vietnam & VESSELS Group in \\
\hline VESSELS Group is a & 2013, <1\% sales, \\
globally operating & increased to 24\% by \\
company that owns 35 & 2015 \\
shipyards in 14 countries & - SP Vietnam is the \\
- VESSELS Vietnam & prioritized supplier in \\
started 2004; 6 joint & Vietnam \\
ventures and & - SP Vietnam proposed to \\
collaborations in Vietnam & set up and manage a \\
- VESSELS Shipyard: & warehouse next to \\
capacity up to 40 boats & VESSELS's warehouse \\
per year & (if a frame agreement \\
\hline
\end{tabular}

\subsection{SP Vietnam and WAKE Shipyard}

In Vietnam, WAKE Vungtau is a fully integrated shipyard that covers activities from hull construction to full vessels delivery. In 2015, 3 of 12 delivered vessels are from this shipyard in Vietnam. With a stellar track record of timely vessel deliveries and positive feedback from our customers, WAKE Vungtau has established itself as a highly valued part of the Group. WAKE Vungtau is currently SP Vietnam's biggest customer. The two groups, SP Group and WAKE Group, have had a long partnership history. The establishment of WAKE Shipyard in Vietnam in 2007 is the main reason leading to the establishment of SP Vietnam in 2009. Besides working based on a frame agreement, the two companies constantly strived to strengthen their relationship. The current relationship between the two companies, according to both companies, is a win-win relationship. This relationship entitles a certain amount of trust from both sides and an attitude of benefits for both. SP Vietnam is the only standard pipes and valves supplier for WAKE Vungtau in the region, but WAKE Vungtau also purchases high pressure pipes and valves from other suppliers in Norway. Regarding operational procedure, WAKE Vungtau and SP Vietnam maintain constant contact and information exchange. Projects' principles are according to Vendor Managed Inventory. WAKE Vungtau's idea in the collaboration with SP Vietnam is that SP Vietnam will be the warehouse to keep WAKE Vungtau's redundant stock, so that WAKE Vungtau will have as few stocks as possible. Therefore, for the items that need to be kept in stock at SP Vietnam's warehouse, SP Vietnam is kept up to date frequently about the items' stock level in WAKE Vungtau warehouse. Additionally, the frame agreement between the two companies stated that SP Vietnam should always have the standard items for 1 ship-set, so that WAKE Vungtau can purchase immediately should there be a sudden project. Other items are purchased based on orders. These items usually are purchased early in the beginning of the project based on a lists sent from WAKE Vungtau, and kept at SP Vietnam's warehouse until WAKE Vungtau needs it and orders it. This strategy, according to SP Vietnam's general manager, is to avoid delay. Information is also updated frequently during a project. WAKE Vungtau's representative conclude that the success of their collaborations are based on the long term history between the two groups. Despite the close relationship, the two companies do not integrate in each other's enterprise system. Information is exchanged solely based on emails, phone calls and meetings. This communication method applies also when WAKE Vungtau has some sudden changes in order and needs to communicate the changes to SP Vietnam. The two partners also do not have capital investment in each other's company. However, a knowledge sharing program has recently been initiated and was set to implement in spring 2016. This program is considered significantly beneficial for both companies, as confirmed by representative from both sides and can be seen as a step towards adoption of electronic data interchange (EDI). Nevertheless, the implementation of the program has been delayed due to the costs saving approach from WAKE Vungtau in order to deal with the current downturn in oil and gas activity.

\subsection{SP Vietnam and Chūbu Shipyard}

SP Vietnam, together with SP Norway has been working with Chūbu Shipyard since December 2014. For its customers, SP Vietnam only supplies pipes, fittings and flanges; other valves packages and high technological items are supplied by SP Norway. SP Vietnam and SP Norway join forces in providing the customer technical expertise in the engineering process, and present to the customer a complete package of items. SP Vietnam's general manager believes that the separated logistics arrangement should not cause troubles for the customer in receiving the items at the warehouse, at least for items sent from SP Vietnam as these are not hightech products. In terms of communication during 
projects, the methods used are mainly emails and phone calls. There is one designated person at SP Vietnam and one designated personal at SP Norway responsible for the Chūbu projects. Throughout all communication, these designated employees are updated constantly with information regardless of whether the issues are related to items from Norway or from Vietnam. This is the first time SP Group works with Chūbu Shipyard, yet Chūbu is already considered an important customer for SP Vietnam, given the relatively significant sales share. Chūbu builds vessels according to both JIS and DNV standards, where JIS is the Japanese Industrial Standard, and DNV is the Norwegian standards (Den Norsk Veritas). The projects that SP Group has been working with Chūbu are for vessels built on DNV certifications, and SP Vietnam believes that should Chūbu plans to build more vessels using this standard, it is possible that the SP Group can be the supplier as the group had good feedback from this customer.

\subsection{SP Vietnam and VESSELS Group Vietnam}

VESSELS Group is a globally operating company that has built over 5,000 vessels for customers in nearly every country in the world, from central Africa to the smallest island in the Pacific, owns 35 shipyards in 14 countries. In 2014, VESSELS bought $70 \%$ of Shipyard-Vietnam shipyard and officially started VESSELS Shipyard-Vietnam Shipyards, the first formal joint venture of the group in Vietnam. Representative from VESSELS Shipyard-Vietnam stated that Vietnam nowadays is the biggest production location for the VESSELS Group, with growing potential.

SP Vietnam started working with the VESSELS Group in 2013 but the sales portion at this time was only about less than 1\%. In 2014 the sales increased to more than 3 million NOK, and by 2015 this number increased significantly to 17 million NOK, which represents about $24 \%$ of the total sales. The reason to collaborate with SP Vietnam, according to VESSELS is that reliability is very important for VESSELS, especially when the company starts approaching the local suppliers. SP Vietnam, working with the Norwegian standards, is considered a reliable supplier that delivers good quality products. To VESSELS Shipyard-Vietnam, SP Vietnam is considered the best supplier in Vietnam at the moment. SP Vietnam has also considered to set up a warehouse, which is $100 \%$ managed by SP Vietnam, next to VESSELS Shipyard-Vietnam's warehouse in Hai Phong, Vietnam. This is considered should a frame agreement be reached.
Regarding communication between the two companies, only emails and phone calls are used to exchange information. The overall quality of communication so far is considered good by both VESSELS Shipyard-Vietnam and SP Vietnam. The communication process started by VESSELS Shipyard-Vietnam generates lists of needed materials from the system and sends to SP Vietnam via email. SP Vietnam then checks the inventory status for the items and gives information for items that need to be purchased, together with the lead-time. Items discussed before the purchasing process are also carried out via email. SP Vietnam stores some standard items for VESSELS Shipyard-Vietnam in the warehouse; however, differences in items' dimensions for some projects are to be expected. Thus, this is an issue that needs to be discussed between the two companies before a PO can be sent.

\section{Analysis of Information Sharing on Collaborative Practices}

\subsection{Information sharing with WAKE}

Information sharing at an operational level can be analyzed via the tactics applied in the day-to-day business relationship between SP Vietnam itself and its customers. Exchanged are inventory status and items' status. Inventory status cover the inventory level of items listed in the frame agreement, as well as items that WAKE keeps in SP Vietnam's warehouse. Items' status including information of items that needs to be ordered from sub-suppliers, and the lead-time for such items.

"...we have good knowledge about what they have in stock or not, because we are informed by them. We are not in their data warehouse, but we are informed by their purchase manager about what they have in stock and what they need, etc. For items that we need to keep on stock here, we know their status there [at WAKE's warehouse]..."(SP Vietnam's general manager, 14/01/16).

Sales data are not exchanged unless there is a special request from either side, according to SP Vietnam's general manager. However, WAKE confirms that sales data from the company, for future projects, are exchanged with SP Vietnam after the contract for new project is signed (WAKE's purchasing manager, 04/05/16). Order status for tracking and tracing is exchanged between the two companies, and delivery information is sent from SP Vietnam to WAKE once the entire package is delivered. Table 2 shows information covering the most important phases of projects exchanged with 
WAKE and other companies. All exchanged information is relevant for the projects. WAKE and SP Vietnam do not share a common warehouse, however the frequency of information exchanged during a project is high: "We have very frequent meetings...we talk together may two, three times a week..." (WAKE's sourcing manager, 14/01/16). Based on these statements and the definitions suggested earlier in the literature review, it can be concluded that the information exchanged between SP Vietnam and WAKE are high quality information.

Table2. Types of shared information

\begin{tabular}{ccc}
\hline $\begin{array}{c}\text { Types of shared } \\
\text { information }\end{array}$ & WAKE & Other customers \\
\hline Inventory level & Exchanged & $\begin{array}{c}\text { Exchanged on } \\
\text { requests }\end{array}$ \\
\hline Sales data & $\begin{array}{c}\text { Shared after a } \\
\text { new contract is } \\
\text { signed (from } \\
\text { VARD) }\end{array}$ & $\begin{array}{c}\text { Exchanged on } \\
\text { requests }\end{array}$ \\
\hline $\begin{array}{c}\text { Order status (from SP } \\
\text { Vietnam) }\end{array}$ & Exchanged & Inform ETA \\
\hline $\begin{array}{c}\text { Production status (from } \\
\text { SP Vietnam) }\end{array}$ & Exchanged & Not exchanged \\
\hline $\begin{array}{c}\text { Delivery status (from SP } \\
\text { Vietnam) }\end{array}$ & Exchanged & Exchanged \\
\hline
\end{tabular}

\subsection{Information sharing with other customers}

SP Vietnam's general manager states (28/04/16), "it appears that information shared with other customers is not as broad and extensive as the information shared with WAKE". Accordingly, inventory level is only shared with WAKE, but level of stocks for requested items can be shared with other customers on requests. This is similar to sales data, both from SP Vietnam's side and from the customer's side. Production status is not shared between SP Vietnam and other customers. Regarding order status for tracking and tracing, SP Vietnam usually inform customers of the estimated time of arrival (ETA). In case of delay, SP Vietnam track and trace the order themselves and then inform the customer of the orders' location as well as the new expected arrival time.

VESSELS Shipyard-Vietnam confirms that the company only shares information about the items that are supplied by SP Vietnam (VESSELS ShipyardVietnam's sourcing manager, 23/03/16). For Chūbu Shipyard, the SP Vietnam's designated employee for Chūbu projects stated "We follow up the project based on the customer's ENQs [enquiries]" $(19 / 04 / 16)$. This statement confirms the practice of information sharing only on request, though it does not directly point out the types of shared information. It can be assumed that only project related information are exchanged in each case. In summary, information shared between SP Vietnam and WAKE is significantly broader and more intensive than that being shared between SP Vietnam and other customers. As can be seen, information shared with other customers is limited in terms of both accessibility as well as availability.

\subsection{Implications of Information sharing at SP Vietnam}

Among all the investigated customers in this study, WAKE is the prioritized partner in terms of information sharing. Shared information between SP Vietnam and WAKE also cover all types of information needed throughout projects, i.e. inventory levels, sales data, order status, production status and delivery status. On the other hand, information shared with other customers does not include production status, while other information types are only exchanged upon requests. Based on this analysis, it is also concluded that the information shared with WAKE is of higher quality than the information shared with other customers.

The communication process also facilitated by simple information exchange method, were emails, phone calls and personal meetings. Personal meetings were arranged extensively between SP Vietnam and WAKE Vungtau during a project. The common information system is only applied between SP Vietnam and its main supplier SP Norway, due to the mother - daughter company characteristic between these two partners. It appears that the lack of external pressure from industrial customers is a strong influence in SP Vietnam's current unintegrated information system (non-use of EDI). Approaching this issue, SP Vietnam stated that the company is willing to upgrade the current information system should there is a request from their customer. A potential request might be coming from WAKE soon. VESSELS Shipyard-Vietnam, on the other hand, approaches the issue via perspective of the future collaboration between the two companies. They see the potential in an integrated information system with SP Vietnam once a frame agreement is reached, and the purchasing volume is significantly higher than the current volume. A practical implication once this happens, it will also encourage that SP Vietnam will be motivated to change to more IT-enabled communicating practices such as EDI.

\section{VMI Concept Applied}

A concept that is close to VMI is being applied as the collaborative supply chain management between the case company and its long term customer. This concept has potential to be applied for new and potential customers. Thus, it will be interesting to 
analyze the different aspects of this applied method. Details of the definition and the VMI application in SP Vietnam are summarized in Table 3 [16].

Table 3. VMI concept - applied

\begin{tabular}{|l|l|}
\hline \multicolumn{1}{|c|}{ Definition } & \multicolumn{1}{c|}{ The applied concept } \\
\hline $\begin{array}{l}\text { Suppliers control the } \\
\text { replenishment }\end{array}$ & $\begin{array}{l}\text { Both supplier (SP Vietnam) and customer } \\
\text { (WAKE) control the replenishment }\end{array}$ \\
\hline $\begin{array}{l}\text { Pre-set performance } \\
\text { standard }\end{array}$ & Frame agreement (1 shipset) \\
\hline $\begin{array}{l}\text { Some information is } \\
\text { transfered from customers } \\
\text { to suppliers }\end{array}$ & $\begin{array}{l}\text { Almost all project related information are } \\
\text { exchanged: inventory level, sales data, } \\
\text { order status, and delivery status }\end{array}$ \\
\hline $\begin{array}{l}\text { No customer's order to } \\
\text { initiate a purchase }\end{array}$ & $\begin{array}{l}\text { - POs are still needed } \\
\text { Items can still stay in SP Vietnam's } \\
\text { warehouse after the PO is received }\end{array}$ \\
\hline $\begin{array}{l}\text { The receiving warehouse } \\
\text { is owned by the customer } \\
\text { or operated by some 3rd } \\
\text { party on his behalf }\end{array}$ & $\begin{array}{l}\text { The receiving warehouse in this case is } \\
\text { owned by WAKE }\end{array}$ \\
\hline
\end{tabular}

Based on the above analysis of the applied collaborative supply chain method at SP Vietnam, this strategy falls within the definition of VMI. In [16], VMR is defined as the replenishment method where goods' ownership is transferred to the customer upon goods arrival at the warehouse, while in VMI, goods belong to customer even when it is still in supplier' warehouse. In this case, there are some of WAKE's items that are not listed in the frame agreement, but are still stored in SP Vietnam's warehouse and jointly managed in SP Vietnam. These items belong to WAKE regardless of SP Vietnam's involvement in the management process. For items that are listed in the frame agreement, as well as other items ordered by WAKE, SP Vietnam can receive the $\mathrm{PO}$ and still keep the items in their warehouse until WAKE needs it at the workshop. Thus, these items also belong to WAKE but are physically and temporarily stored in SP Vietnam's warehouse. Clearly, based on this classification, the method applied at SP Vietnam towards WAKE falls into the concept of VMI.

\subsection{Trust in Information Sharing}

Representatives from both company confirmed the role of trust in this relationship. The collaborative strategy was initiated mainly due to the long term relationship between WAKE Group and SP Group in Norway. The establishment of SP Vietnam as well as the idea of SP Vietnam being a second warehouse for WAKE in Vietnam was initiated by WAKE. However, that statement that SP Vietnam will be the warehouse for WAKE redundant items is not a part of the frame agreement, but rather an informal mutual agreement between the two companies. Clearly, by agreeing to this condition, SP Vietnam took on itself the risk of not having enough space for other customers' stock in the warehouse, thus making it difficult to serve other customers, should WAKE's business reduce. The fact that SP Vietnam agreed upon this condition and continuously working with this informal promise shows significant level of trust in WAKE. In return, SP's consistency in keeping service level not only according to the frame agreement but also informal agreement increases WAKE's trust in SP Vietnam. Studies have shown that a long history of working together creates the shared understanding of task requirements [22]. This can be considered an important basis for further and closer collaboration, which can be argued as one factor that leads to trust development. In this case, the long collaboration history between SP Group and WAKE Group in general and between SP Vietnam and WAKE Vungtau in particular, can be seen as one factor that helps to develop the current level of trust. This is confirmed by both companies, as a win-win relationship. Extensive personal meetings and information exchange between the two companies during project processes also indicate the development of mutual trust and understanding between two partners [23]. According to the author, project-wide communication in the early phase were found to influence the participants' behavior and general knowledge, so that trust-based collaboration is more likely to arise and persist.

\subsection{Other Areas of Collaboration}

In this case, the two companies joined forces in inventory management process, production process and design (engineering) process. The two companies also have plans for a warehouse management knowledge sharing program, however the actual implementation of the program is delayed due to the current costs cutting strategies from WAKE. There is no joint collaboration in forecast or sales. The lack of collaboration in these two areas can be due to the market characteristics of shipbuilding industry, is said to be strongly project driven and significantly unpredictable with a lot of ups and downs.

\section{Discussion}

This paper utilizes the collaborative model [20] focusing on areas of collaboration as stated in Table 4. Based on this classification we can compare the shapes of the cartographies in Figure 2. By comparing the shapes of the cartographies, one can observe the differences between the collaborative strategies being applied in the case company. Different shapes of the above cartographies indicate clear differences in collaborative strategies between 
SP Vietnam and each of its customers. There are common collaborative patterns between SP Vietnam and its customers in terms of the extent, context and nature of the collaboration. The current collaboration between SP Vietnam and each of its customers does not involve the entire supply chains at both sides. The extent of the collaboration is only at Bi-levels of inter-enterprise integration. The characteristics of the shipping industry and its ETO environment requires SP Vietnam to always provide customers with technical knowledge and expertise, thus it is concluded that the context of collaboration between the company and its customers is at expertise level. Information is exchanged quite extensively between SP Vietnam and its customers, especially to WAKE Vungtau. However, an integrated performance system has not been used. Thus, the nature of collaboration remains at exchanging rather than sharing, as there has not been any common development or using of data by the two companies.

Table 4. Patterns of information sharing

\begin{tabular}{|c|c|c|c|c|c|}
\hline Area & Level 1 & Level 2 & Level 3 & Level 4 & Level 5 \\
\hline Extents & $\begin{array}{l}\text { Intra- } \\
\text { enterprise }\end{array}$ & $\begin{array}{l}\text { Inter- } \\
\text { enterprise: } \\
\text { Bi-levels }\end{array}$ & $\begin{array}{l}\text { Inter- } \\
\text { enterprise: } \\
\text { Multi-levels }\end{array}$ & $\mathrm{N} / \mathrm{A}$ & N/A \\
\hline Context & Data & Information & Knowledge & Expertise & Capability \\
\hline Nature & $\begin{array}{l}\text { Objects } \\
\text { available }\end{array}$ & Exchange & Share & N/A & N/A \\
\hline Level & Operational & Tactical & Strategic & N/A & $\mathrm{N} / \mathrm{A}$ \\
\hline
\end{tabular}

Extents

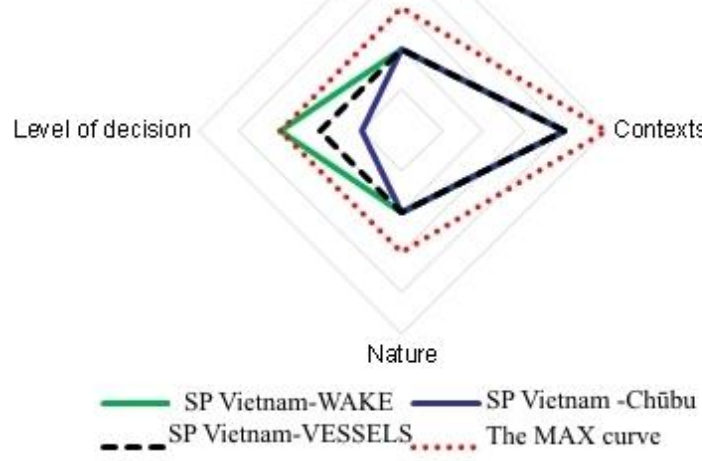

Figure 2. Collaborative strategies - customers

The level of decision is observed to be at optimal level for the collaboration between SP Vietnam and WAKE Vungtau only, due to the trust built up from a long term partnership. This area of collaboration between SP Vietnam and Chūbu is observed to be at operational level only, while the collaboration with VESSELS is currently at operational level, with the potential to reach strategy level once the frame agreement can be obtained.
Regarding plans to outreach for new collaborations, interviews with SP Vietnam (sourcing manager, 14/01/16), confirmed that in the area of operational tactics that "communication and information exchange with customers or suppliers in the region (China and South East Asia) always need to be very precise."

A theoretical implication of this study is it aligns with prior research $[18,19]$ that for strategic level decisions is that cultural aspects are important. Management noted, "Corruption in Vietnam stops the company from reaching out to some local suppliers and customers as we are not doing anything like this (corruption), such that some contracts that could have been signed were not signed." They concluded that if SP Vietnam are to expand, they will do so only with other customers "who are thinking as we are."

A practical implication in this case is the ability to apply VMI without the needs of an inter-enterprise system. In most VMI literature, the role of a sophisticated information system is always highlighted. However, in this case, clearly SP and WAKE can establish a VMI relationship without such IT that are based solely on standard communication. It should be noted that this is possibly enabled due to the characteristics of the shipbuilding industry (customization = extensive amount of information to be exchanged at personal level), and the high level of trust. In brief, the implication for other companies in shipbuilding industry (the application area of the paper) is the possibly to establish a VMI relationship using standard information exchange methods, as long as there is high level of trust among partners.

\section{Conclusions}

SP Vietnam applies collaboration practices at the operational level where it applies VMI for one customer WAKE. It implements a broad but selective information sharing strategy using simple methods for sharing information that are not based on fully integrated systems. The case study also revealed that there are certain commonalities in SP Vietnam's collaborative strategies with its different customers. Our findings in this study are limited in that they are based on analysis of one focal company and three of its largest customers. However, the study company and its customers are successful and long established in their industries and regions. As such, they are major participants in their industries, and have experience as multicultural companies. We think that smaller companies would find their experiences to be informative and therefore of strategic value. 
Our study concluded that the practices applied with WAKE are at the highest level of quality, compared to the other customers and are based on a long term relationship of trust. Trust develops over numerous interactions between companies, building a trust relationship. We conclude that trust or the trust relationship is seen as a prerequisite for the application of VMI and further as a basis for planning of more IT-enabled information exchange. The major implication is potential for similar developments with other partners, and this approach in the long run could aid SP Vietnam to reach out to new customers.

\section{References}

[1] H.L. Lee, V. Padmanabhan, and S. Whang, "The bullwhip effect in supply chains", Sloan Management Review, 38(3), 1997, pp. 93-102.

[2] H.L. Lee, and S. Whang, "Information sharing in a supply chain", International Journal of Manufacturing Technology and Management, 1(1), 2000, pp. 79-93.

[3] D. Boddy, A. Boonstra, and G. Kennedy, "Managing information systems: Strategy and organization", Pearson Education, 2008.

[4] H. Zhou, and W.C. Benton, "Supply chain practice and information sharing", Journal of Operations Management, 25(6), 2007, pp. 1348-1365.

[5] H. Forslund, "Measuring information quality in the order fulfilment process", International Journal of Quality \& Reliability Management, 24(5), 2007, pp. 515-524.

[6] S. Li, and B. Lin, "Accessing information sharing and information quality in supply chain management", Decision support systems, 42(3), 2006, pp.1641-1656.

[7] A. Malhotra, S. Gosain, S. and O.A.E. Sawy, "Absorptive capacity configurations in supply chains: gearing for partner-enabled market knowledge creation", MIS quarterly, 2005, pp.145-187.

[8] T.M. Simatupang, and R. Sridharan, R., "The collaborative supply chain", The International Journal of Logistics Management, 13(1), 2002, pp.15-30.

[9] A. Harrison, and R.I. Van Hoek, "Logistics management and strategy: competing through the supply chain", Pearson Education, 2008.

[10] P. Seung-Kuk and P.K. Bagchi, "Understanding the causes of the bullwhip effect in a supply chain", International Journal of Retail \& Distribution Management, 35(4), 2007, pp. 308-324.

doi:http://dx.doi.org/10.1108/09590550710736229

[11] C. Carlsson, and R. Fullér, "Reducing the bullwhip effect by means of intelligent, soft computing methods",
System Sciences, Proceedings of the 34th Annual Hawaii International Conference, IEEE, 2001 (pp. 10-20.

[12] M.S. Elvander, "Introducing a structure for the vendor managed inventory concept", work in progress paper at the 18th annual NOFOMA conference, Logistics in the new valley, BI Norwegian School of Management, 2006.

[13] T.L. Pohlen, and T.J. Goldsby, "VMI and SMI programs, how economic value added can help sell the change", International Journal of physical distribution and logistics management, 33(7), 2003, pp. $565-581$.

[14] A.F. De Toni and E. Zamolo, "From a traditional replenishment system to vendor-managed inventory", International Journal of Production Economics, 96(1), 2005, pp. 63-79.

[15] A. Vigtil, "A framework for modelling of vendor managed inventory", Department of Production and Quality Engineering, Dissertation, Norwegian University of Science and Technology, 2008.

[16] A. Vigtil, "Information exchange in vendor managed inventory" International Journal of Physical Distribution \& Logistics Management, 37(2), 2007, pp. 131-147.

[17] D. Simchi-Levi, P. Kaminsky, and E. Simchi-Levi, "Designing and managing the supply chain, concepts, strategies and case studies", McGraw Hill, 2000.

[18] Cheng X., Yin G.P., Azadegan A., Kolfschoten G.L. (2016).Trust Evolvement in Hybrid Team Collaboration: A Longitudinal Case Study, Group Decision and Negotiation, 25(2), 267-288.

[19] Cheng X., Fu S., Sun J., Han Y., Shen J. and Zarifis A.(2016).Investigating individual trust in semi-virtual collaboration of multicultural and unicultural teams, Computers in Human Behavior, 62, 267-276.

[20] R. Derrouiche, G. Neubert, and A. Bouras, "Supply Chain Management: A framework to characterize the Collaborative Strategies", International Journal of Computer Integrated Manufacturing (IJCIM), 21(4), 2008, pp. $426-439$.

[21] T. A. Beckman, "Methodology for Knowledge Management, International Association of Science and Technology", Development AI and Software Computing Conference, Banff, Canada, 1997.

[22] A. Windeler, and J. Sydow, "Project networks and changing industry practices collaborative content production in the German television industry", Organization Studies, 22(6), 2001, pp. 1035-1060.

[23] A. Kadefors, "Trust in project relationships-inside the black box", International Journal of Project Management, 22(3), 2004, pp. 175-182. doi:http://dx.doi.org/10.1016/S0263-7863(03)00031-0 